\title{
A flume study to investigate the contribution of main-channel bedforms on levee formation
}

\author{
Till Branß $\aleph^{1, *}$, Francisco Núñez-González ${ }^{1}$, Andreas Dittrich ${ }^{1}$, and Jochen Aberle ${ }^{1}$ \\ ${ }^{1}$ Leichtweiß-Institut für Wasserbau, Technische Universität Braunschweig, Germany
}

\begin{abstract}
Natural levees can be observed worldwide in nearly all river systems characterized by frequent flooding in combination with the transport of suspended bed material. Several parameters and processes have been suggested to explain the formation and the highly variable geometry of natural levees. However, the effect of bedforms migrating in the main-channel has not been amongst the studied parameters and processes. To fill this gap, this study investigates the relationship between bedforms and natural levee formation by flume experiments. Experiments were conducted in a $2 \mathrm{~m}$ wide and $30 \mathrm{~m}$ long sediment recirculating flume, monitoring the bed level elevation in the main channel by ultrasonic sensors as well as recording the levee development on the floodplain by a camera. The effect of different bed configurations on the developed levees is compared, and discussed, showing that bedforms could enhance levee formation.
\end{abstract}

\section{Introduction}

Natural levees are narrow elevated sediment deposits along the floodplain edge of compound channels. They have been found in natural streams worldwide and can be observed in nearly all river systems which are characterized by frequent flooding in combination with transport of suspended bed material [1,2]. Natural levees are formed by suspended sediment which is transported from the main channel onto the floodplain edges; i.e. overbank flow is a prerequisite for the formation of natural levees and these morphological structures grow gradually with every flood event overtopping the levee crests.

Natural levees have been described in many field studies (e.g. [3, 4, 5, 6,]), and different processes have been suggested to explain their formation and highly varying geometry. For example [7] related the diversity in levee geometry to different mechanisms of lateral sediment transfer. They suggested that levees generated by turbulent shear between the main channel and floodplain exhibit a narrow and steep geometry while levees resulting from advective transport, caused by differences in the water surface elevation between the main channel and floodplain, tend to be wider and less steep. Other studies (e.g. [8]) revealed a strong relation between overbank sediment transfer and the water depth ratio between the main channel and the floodplain. Although these studies helped to identify the

* Corresponding author: t.branss@tu-bs.de 
basic processes leading to the formation of natural levees, a detailed understanding of the relevant processes is still lacking.

In this context, previous studies focusing on levee formation in laboratory experiments $[11,12,13]$ have not looked at the influence of the main channel bed configuration on levee formation. Especially bedforms such as dunes can be important as they may enhance the suspension of sediment above their crest (e.g. [9, 10]) so that larger concentrations of bed sediment at high levels of the water column may be expected. Such larger sediment concentrations can lead to an increased transport of bed sediment onto the floodplain which in turn can favour levee formation.

This paper examines the relationship between bedforms and natural levee formation. Preliminary results of flume experiments are presented in which natural levees have been successfully reproduced with and without bedforms in the main channel. The effect of different bed configurations on levee characteristics is investigated and conclusions are drawn regarding the effect of bedforms on levee formation.

\section{Experimental setup}

Experiments were conducted in a $2 \mathrm{~m}$ wide and $30 \mathrm{~m}$ long, tiltable sediment recirculating flume in the hydraulic laboratory of the Leichtweiß-Institut für Wasserbau at the Technische Universität Braunschweig, Germany. A $20 \mathrm{~m}$ long test section was built in the flume starting at a distance of $4 \mathrm{~m}$ from the flume inlet (Fig. 1). The test section consisted of a half trapezoidal compound channel which had a floodplain width of $130 \mathrm{~cm}$ and a bed width of $60 \mathrm{~cm}$. The slope of the main channel bank was 1:1 resulting in bank height of $10 \mathrm{~cm}$ and a bankfull half-channel width of $70 \mathrm{~cm}$. The main channel bed was constructed from film faced plywood plates to which a single layer of fixed polystyrene granulate grains were glued as roughness elements $(d=2.06 \mathrm{~mm}$; see below). Artificial grass with a height of $3 \mathrm{~cm}$ was used to simulate roughness on both the bank and the floodplain. The coordinate system was defined as shown in Fig 1 and 2, with the x-axis in flow direction, $y$ being the lateral direction and $\mathrm{z}$ pointing upwards, with its origin on top of the fixed main channel bed.

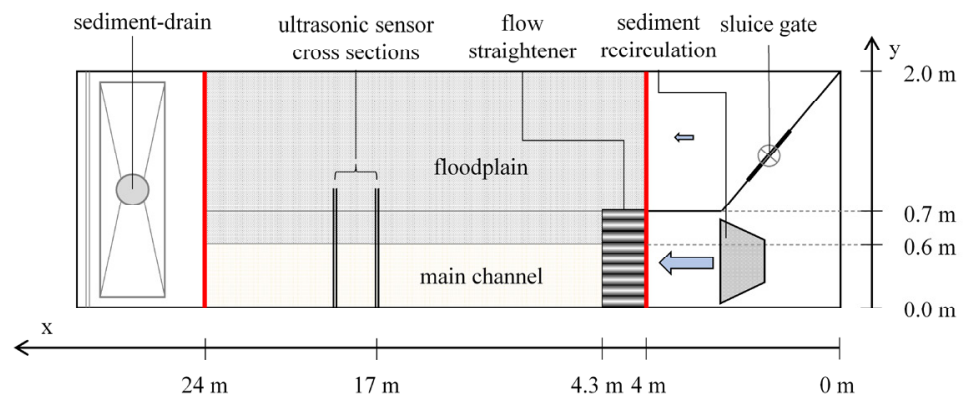

Fig. 1. Schematic plan view of the flume set up (flow direction right to left)

The channel was separated into two parts in the $4 \mathrm{~m}$ long section spanning the distance from the flume inlet to the beginning of the test section. This separation allowed for the control of the discharge distribution between the main channel and floodplain by means of a built-in sluice gate (Fig. 1). The purpose of this setup was to impede advective flow between the channel sections and shorten the development length of the shear layer [14].

Polystyrene granulate was used as surrogate sediment to accelerate morphodynamical development. The polystyrene grains were of cylindrical shape, had a diameter of $2.06 \mathrm{~mm}$, a solid density of $\rho_{\mathrm{s}}=1058 \mathrm{~kg} / \mathrm{m}^{3}$, and their critical velocity for initiation of motion 
corresponded to $\mathrm{u}_{\text {crit }}=9.5 \mathrm{~cm} / \mathrm{s}$ [15]. During the experiment the sediment was constantly recirculated using a sediment recirculation circuit consisting of a funnel-shaped sediment collection tank at the end of the flume, a return pipe, and a sediment feeder upstream of the main channel (Fig.1).

All experiments were carried out with a constant bed slope $S=0.0005$, quasi uniform flow conditions and the same duration of $19.5 \mathrm{~h}$. This duration was chosen based on findings from preliminary experiments which showed that the levee reached a nearly stable state after this time for the given boundary conditions.

\subsection{Measurements}

The total discharge in the test section corresponded to the sum of the discharges supplied through the laboratory water circuit and the sediment recirculation circuit. Both discharges were measured with magnetic-inductive flow meters. The sediment transport rate in the flume was continuously monitored during the experimental runs within the return pipe of the sediment recirculation system. The corresponding transport rates were determined by relating turbidity measurements obtained by a Negele four-beam turbidity meter to sediment concentration using specific calibration curves.

Mean surface flow velocities in the main channel and floodplain were estimated by tracking floats over a given distance and measuring their travel-time with a chronometer. The surface velocities reported below represent the average of 3 measurements. Water levels were manually measured every two meters with a point gauge mounted on a manual traverse. Bed levels in the main channel were continuously recorded with 16 ultrasonic sensors (SeaTek $5 \mathrm{MHz}$ Ultrasonic Ranging System) in two cross-sections located at distances of $\mathrm{x}=17 \mathrm{~m}$ and $\mathrm{x}=17.81 \mathrm{~m}$ from the flume inlet (see Figs. 1 and 2). In each cross section, 8 sensors were mounted with a spacing of $8 \mathrm{~cm}$ (as shown in Fig. 2). Each recorded value consisted of an average of 10 readings to minimize distortions by suspended sediment. The corresponding recording interval was $0.35 \mathrm{~s}(2.9 \mathrm{~Hz})$. For data analysis the bed elevation data had to be further smoothed to reduce noise introduced into the signals by suspended particles. For this purpose, a moving average over 50 measuring points was applied.

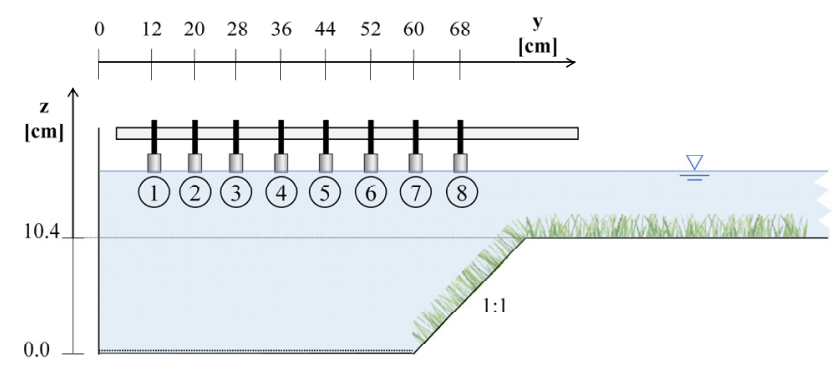

Fig. 2. Lateral positioning of ultrasonic sensors in the main channel cross section.

The levee development was monitored with plan view photos which were automatically taken each $5 \mathrm{~s}$ by a camera covering the region between the bed level monitoring crosssections. After each experiment the final levee configuration was documented and recorded along the entire flume with photos, manual measurements of levee geometry with a point gauge, and a laser displacement meter attached to a traverse system. The material forming the levee deposits was collected in $60 \mathrm{~cm}$ long sections over the flume length and weighed to determine the mass of deposited sediment. 


\subsection{Experimental program}

Five experiments were conducted to investigate the impact of bedform configuration on the formation of natural levees. Each experiment was controlled by the total amount of lightweight material in the flume, so that differences in the amount of sediment in the main channel at the beginning of the experiments led to different sediment transport rates and bedform characteristics. All experiments were conducted under supply limited conditions in order to ensure that the material was in movement all along the entire channel, and that the slope of the average longitudinal profile was approximately the same between runs with different amounts of sediment.

Bedforms were present in 3 of the 5 runs. The two runs without bedforms served as control runs to identify the impact of bedforms. For these two runs the water discharge was increased to impede the formation of bedforms in the main channel, with most of the lightweight sediment being transported in suspension. This resulted in sediment transport rates of the same magnitude as in the experiments with bedforms. Water stages in the main channel and the floodplain were kept almost constant between the 5 experimental runs, with values of $16 \pm 0.5$ and $5.6 \pm 0.5 \mathrm{~cm}$, respectively. Before starting an experiment, the bed in the main channel was screeded while filling the flume with water, and the artificial grass was brushed to assure comparable starting conditions. Table 1 summarizes the experimental runs providing information on hydraulic boundary conditions.

Table 1. Conducted experimental runs with qsed as sediment transport rate, $\mathrm{Q}$ the total water discharge, $h_{\mathrm{f}}$ and $\mathrm{h}_{\mathrm{mc}}$ the water level on the floodplain and in the main channel, and $\mathrm{u}_{\mathrm{mc}}$ and $\mathrm{u}_{\mathrm{f}}$ describing the mean surface velocity in the main channel and on the floodplain, respectively.

\begin{tabular}{|c|c|c|c|c|c|c|}
\hline $\begin{array}{l}\text { Run } \\
\text { No. }\end{array}$ & Bed forms & $\begin{array}{c}\text { qsed } \\
{[\mathrm{g} /(\mathrm{s} \mathrm{m})]}\end{array}$ & $\begin{array}{c}\mathrm{Q} \\
{[1 / \mathrm{s}]}\end{array}$ & $\begin{array}{c}\mathrm{h}_{\mathrm{f}} / \mathrm{h}_{\mathrm{mc}} \\
{[-]}\end{array}$ & $\begin{array}{c}\mathrm{u}_{\mathrm{mc}} / \mathrm{u}_{\mathrm{crit}} \\
{[-]}\end{array}$ & $\begin{array}{c}\mathrm{umc}_{\mathrm{mc}} / \mathrm{uf}_{\mathrm{f}} \\
{[-]}\end{array}$ \\
\hline 1 & with & 24.5 & 22 & 0.40 & 2.70 & 2.6 \\
\hline 2 & with & 40.4 & 22 & 0.43 & 2.9 & 2.8 \\
\hline 3 & with & 57.2 & 22 & 0.45 & 3.1 & 2.7 \\
\hline 4 & without & 42.0 & 32 & 0.35 & 3.7 & 3.7 \\
\hline 5 & without & 54.7 & 32 & 0.36 & 4.1 & 3.7 \\
\hline
\end{tabular}

\section{Results}

\subsection{Bedform characteristics}

The standard deviation of the filtered data, for all the three experiments with bedforms, showed that the time required for achieving a full development of the bed configuration was always shorter than one hour. This period was not considered for further analysis.

For the analysis, the height of individual bedforms was identified from the ultrasonic data by searching for peak elevations of more than $1 \mathrm{~cm}$ above the fixed bed level with the additional condition of a minimum temporal lag between two subsequent peaks of around $30 \mathrm{~s}$. The cumulative distribution of peak elevations from all sensors in the upstream crosssections is shown in Fig. 3. Assuming that the peak elevations can be used as a surrogate measure for the bed form heights, the figure shows that the median bedform heights were $3.6,5.0$ and $5.5 \mathrm{~cm}$, for runs 1,2 and 3, respectively; this means that the median bedform height increased with sediment transport rate. 
The comparison of bed elevation distributions in the cross-sections showed that for runs 2 and 3 the bedform height decreased laterally, being in average larger close to the floodplain than close to the flume wall. The bedform heights in run 1 did not exhibit any significant lateral trend. In all three runs bedforms where mostly retarded at the bank side, showing a slight crescent-shaped form in plan view, so that the bed configurations were always three-dimensional.

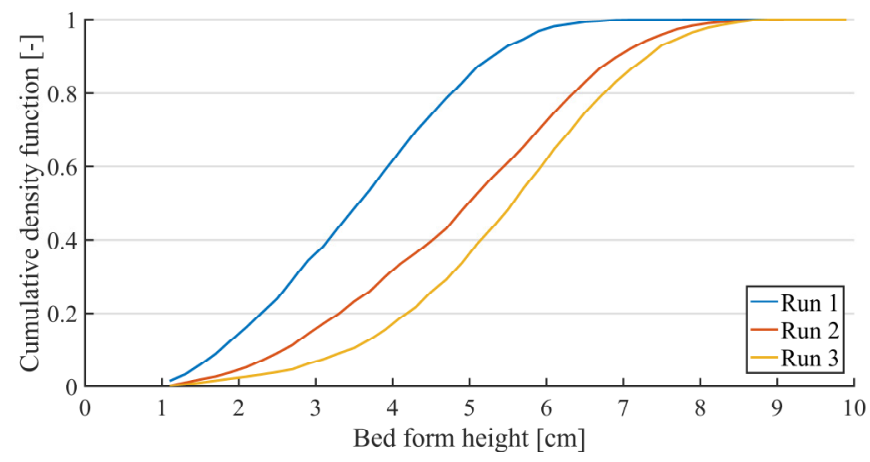

Fig. 3. Relative cumulative density function of bedform elevations

\subsection{Final levee geometry}

Figure 4 shows a plan view of the different levees formed in the five experimental runs.
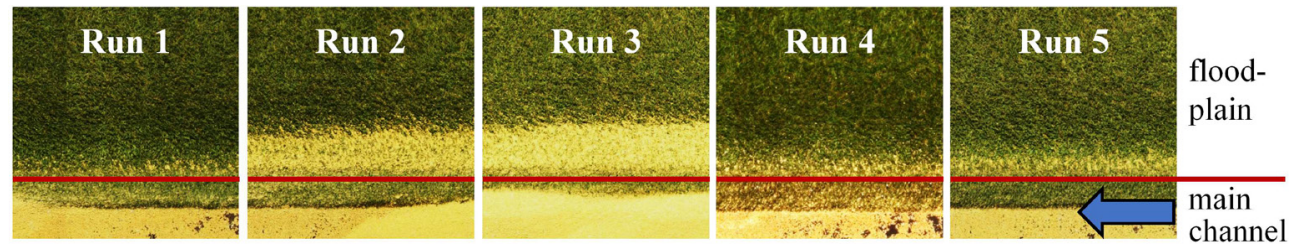

Fig. 4. Levees formed in the five experiments (line marks the edge of the floodplain)

Table 2 summarises the observed maximum levee width, the levee mass, and the amount of transported sediment and shows that the deposition and levee formation was more pronounced during runs 2 and 3 compared to run 1. Both width and mass of the deposited levee material was highest for run 3, i.e., the run with the highest bedforms and lowest for run 1 (smallest bedforms). For the runs without bedforms (runs 4 and 5), the levee mass was of the same order of magnitude as for run 1, but the levee width was larger in runs 4 and 5 than in run 1.

Table 2. Experimental results

\begin{tabular}{|c|c|c|c|c|c|c|}
\hline $\begin{array}{c}\text { Run } \\
\text { No. }\end{array}$ & qsed & $\begin{array}{c}\text { Mean } \\
\text { bed } \\
\text { level } \\
{[\mathrm{cm}]}\end{array}$ & $\begin{array}{c}\text { Median } \\
\text { bedform } \\
\text { height } \\
{[\mathrm{cm}]}\end{array}$ & $\begin{array}{c}\text { Max. } \\
\text { levee width } \\
\text { ymax } \\
{[\mathrm{cm}]}\end{array}$ & $\begin{array}{c}\text { Levee } \\
\text { mass } \\
{[\mathrm{g} / \mathrm{m}]}\end{array}$ & $\begin{array}{c}\text { tot. levee mass/ } \\
\text { tot. transported } \\
\text { sediment } \\
{[-] 10^{-3}}\end{array}$ \\
\hline 1 & 24.5 & 1.5 & 3.6 & 5.7 & 52.6 & 1.0 \\
\hline 2 & 40.4 & 2.4 & 5.0 & 16.8 & 446.5 & 5.2 \\
\hline 3 & 57.2 & 3.3 & 5.5 & 20.0 & 666.4 & 5.5 \\
\hline 4 & 42.0 & 0 & 0 & 11.1 & 56.4 & 0.6 \\
\hline 5 & 54.7 & 0 & 0 & 11.7 & 117.1 & 1.0 \\
\hline
\end{tabular}




\subsection{Levee development}

For runs with bedforms (runs 1 to 3), the temporal evolution of the levee formation was investigated by comparing the plan view greyscale photo-series. For this purpose, the contrast between the monochromatic (yellow) particles and the underlying artificial grass was analysed. This provided information on the lateral distribution and amount of the levee sediments for each time step. For a direct comparison between experimental runs it was assumed that the maximum area covered with particles at the end of the run is proportional to the measured average sediment mass per meter (see Fig. 5). This method assumes that the thickness of the sediment deposits was the same between runs, which was supported by the fact that the levee heights were always limited by the height of the artificial grass. The grass trapped particles, but particles deposited above the level of the grass were immediately remobilised and returned to the main channel (see [15]).

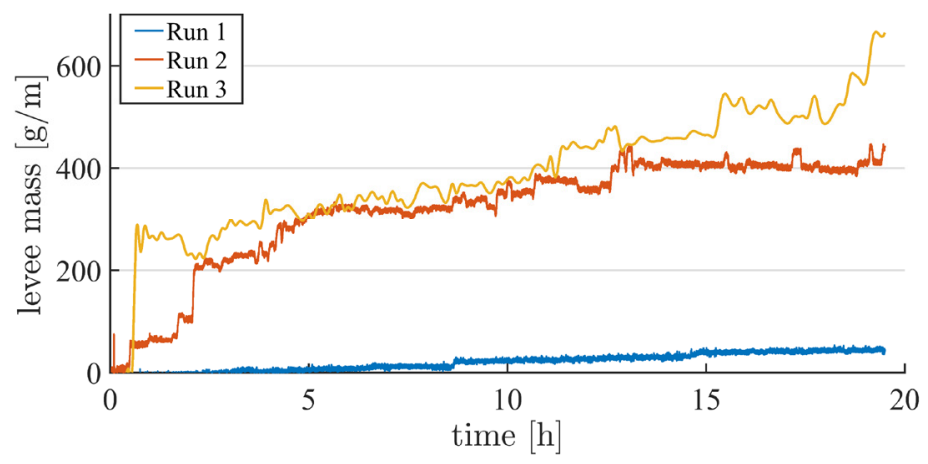

Fig. 5. Temporal development of levee mass

For runs 2 and 3, the temporal evolution of the levee mass was non-uniform (Fig. 5) and large sedimentation rates could be noticed in the early stages of the experiments. The comparison of the peak elevation distributions (Fig. 3) and the accumulation of sediment in the floodplain levee (Fig. 6) shows that the largest sedimentation rates were associated with the occurrence of single large bedforms being higher than the bedform height corresponding to $80 \%$ quartile of the cumulative bedform height distribution (Fig. 3). Even when the levee deposits increased regularly with time, single events associated with the passage of high bedforms could account for as much as $22 \%$ of the total accumulated levee sediment in run 2 , and even $40 \%$ in run 3.

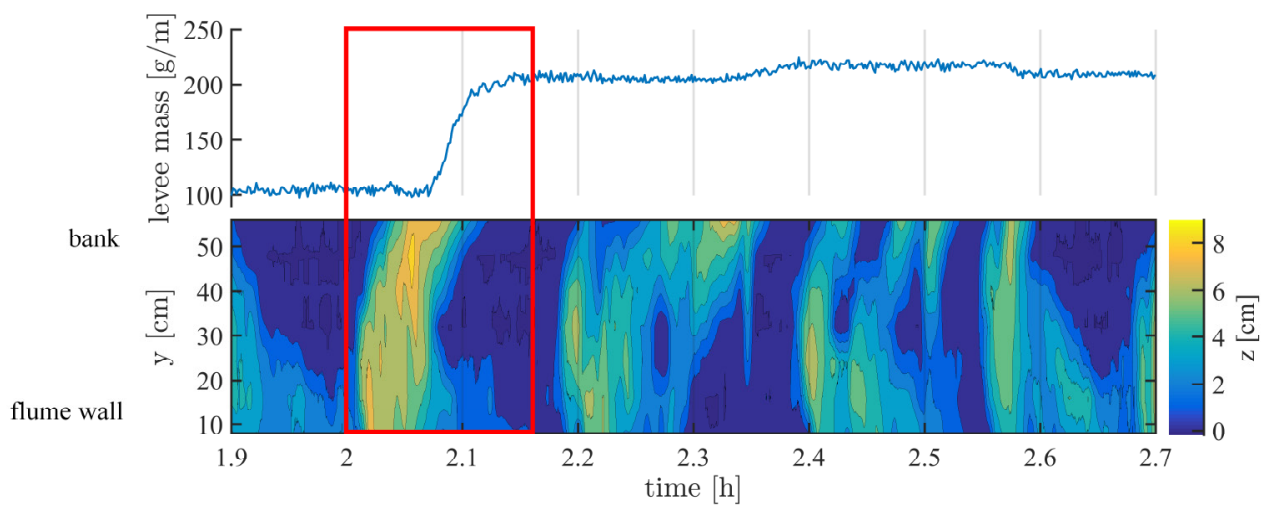

Fig. 6. Sudden increase in levee development due to the passage of a single high bedform (Run 2) 


\section{Discussion}

Runs 2 and 3 were characterized by the largest amounts of levee deposits (see Fig. 4). Moreover, it can be inferred that the levee in run 3 (with the highest bedforms) would have further grown if the experimental time would have been extended, as a stable deposit was not reached when the experiment was stopped (see the trend in Fig. 5 for the last time stages of run 3). The mass of deposited sediment for runs 2 and 3 was 6 and 8 times larger than for runs 4 and 5, i.e. the runs which were characterized by similar transport rates but showed no bedforms. Normalizing the mass of levee sediment with the total mass of sediment transported (see the last column of Table 2), it was found that the percentage of deposited sediment was approx. five times larger for runs 2 and 3 compared to the other runs. This indicates that high bedforms contribute to levee formation.

The sediment transport rates in the runs with and without bedforms were similar, but the flow velocities in the main channel were larger and more sediment was in suspension when bedforms were absent (runs 4 and 5). However, the amount of sediment transferred to the floodplain was larger for the runs with bedforms indicating that the occurrence of bedforms enhanced the lateral diversion of suspended material to the floodplain. For bed sediment being transferred to the floodplain, the particles need to be transported in suspension over the bank (or levee), i.e. the movement of the particles must also contain a lateral component directing them towards the floodplain. A large number of particles in suspension does not necessarily lead to the formation of a levee if the lateral component is absent. It can therefore be concluded that the bedforms in the experiments have not only contributed to an enhanced suspension of particles at high water levels, but also to direct them laterally.

Figure 6 is a strong indicator for the relevance of the bedform-height to levee development. The bedform which contributed significantly to levee formation corresponded roughly to the $98 \%$ quartile of the distribution of bedform elevations (Fig. 3), and this single bedform accounted for $25 \%$ of the total amount of levee sediment for run 2 . In Figure 6 it can be observed that close to the bank the bedform is slightly curved. Thus, it can be hypothesized that this curvature contributes to a lateral component of the movement of particles suspended from the stoss-side of the bedform. Nevertheless, a more detailed analysis is required to identify the role of single high bedforms and bedform threedimensionality on the lateral transfer of particles and levee formation.

\section{Conclusion}

- Experiments were performed to investigate the role of bedforms on natural levee formation

- $\quad$ runs with high bedforms were much more efficient in directing sediment to the plain (resulting in levee formation), even when sediment in suspension was similar in runs with and without bedforms

- the amount of sediment transferred to the plain is not necessarily correlated with the amount of sediment in suspension, so that the development of high bedforms enhances the lateral diversion of suspended material to the floodplain.

- $\quad$ when bedforms were present the mean bed level was higher. This and the periodic increase of bed level as the bedforms migrate contribute to deliver particles to high levels along the water column.

- The role of the bedform three-dimensionality and of single extreme high bedforms still needs to be studied in more detail. Also, the effect of bedforms on the geometry of the levee requires deeper analysis. 


\section{Acknowledgement}

We gratefully acknowledge the work of Andrea Rodler who assisted us with collecting the data for this study.

The work was conducted in the framework of the research project „In_StröHmunG“, founded by the German ministry of Education and Research (BMBF) and is part of the support measure "ReWaM", as well as the funding priority "NaWaM".

\section{References}

1. G.J. Brierley, R.J. Ferguson, K.J. Woolfe, Sediment. Geol. 114, 1-9 (1997)

2. P.F. Hudson, The Int. Encyclopedia of Geography (2017)

3. H.J. Pierik, E. Stouthamer, K.M. Cohen, Geomorphology 295, 215-234 (2017)

4. J.E. Pizzuto, Sedimentology 34, 301-317 (1987)

5. R.J. Ferguson, G.J. Brierley, Sedimentology 46, 627-648 (1999)

6. M. Filgueira-Rivera, N.D. Smith, R.L. Slingerland, Sedimentology 54, 905-919 (2007)

7. P.N. Adams, R.L. Slingerland; N.D. Smith, Geomorphology 61, 127-142 (2004)

8. D. Cazanacli, N.D. Smith, Geomorphology 25, 43-55 (1998)

9. R.A. Kuhnle, D.G. Wren, J. Geophys. Res. 114 (2009)

10. S. Naqshband, J.S. Ribberink, D. Hurther, S.J.M.H. Hulscher, J. Geophys. Res. Earth Surf. 119, 1043-1063 (2014)

11. Q.Fraselle, D.Bousmar, Y.Zech, Proc. River Flow, 823-830 (2010)

12. T. Tsujimoto, J. Hydraul. Res. 37, 789-803 (1999)

13. C.S. James, J. Hydraul. Res. 23, 435-452 (1985)

14. D. Bousmar, N. Rivière, S. Proust, A. Paquier, R. Morel, Y. Zech, J. Hydraul. Eng. 131, 408-412 (2005)

15. B. Ettmer, S. Orlik, Nachbildung von Sieblinien aus künstlichen Sohlenmaterialien in experimentellen Untersuchungen (Report, HSMD, 2012)

16. T. Branß, A. Dittrich, F. Núñez-González, Proc. River Flow, 1122-1128 (2016) 